\title{
Azithromycin Inhibits Mucus Hypersecretion from Airway Epithelial Cells
}

\author{
Takeshi Shimizu and Shino Shimizu \\ Department of Otorhinolaryngology, Shiga University of Medical Science, Seta, Tsukinowa, Otsu, Shiga 520-2192, Japan \\ Correspondence should be addressed to Takeshi Shimizu, Shimizu@belle.shiga-med.ac.jp
}

Received 16 January 2012; Revised 27 February 2012; Accepted 2 March 2012

Academic Editor: Kazuhito Asano

Copyright ( $) 2012$ T. Shimizu and S. Shimizu. This is an open access article distributed under the Creative Commons Attribution License, which permits unrestricted use, distribution, and reproduction in any medium, provided the original work is properly cited.

\begin{abstract}
To examine the in vivo effects of the 15-member macrolide, azithromycin (AZM), on mucus hypersecretion, we induced hypertrophic and metaplastic changes of goblet cells in rat nasal epithelium by intranasal instillation of ovalbumin (OVA) in OVAsensitized rats, or by intranasal lipopolysaccharides (LPS) instillation. Oral administration of AZM (5-10 mg/kg) or clarithromycin (CAM, 5-10 mg/kg) significantly inhibited OVA- and LPS-induced mucus production, whereas josamycin (JM) or ampicillin (ABPC) showed no effect. In vitro effects of AZM on airway epithelial cells were examined using NCI-H292 cells and human nasal epithelial cells cultured in air-liquid interface. Mucus secretion was evaluated by enzyme-linked immunosorbent assay using an anti-MUC5AC monoclonal antibody. AZM or CAM significantly inhibited tumor necrosis factor- $\alpha$ (TNF- $\alpha)(20 \mathrm{ng} / \mathrm{mL})$-induced MUC5AC secretion from NCI-H292 cells at $10^{-6}-10^{-7} \mathrm{M}$, whereas JM or ABPC showed no effect. AZM significantly inhibited TNF- $\alpha(20 \mathrm{ng} / \mathrm{mL})$-induced MUC5AC secretion from human nasal epithelial cells at $10^{-4} \mathrm{M}$. MUC5AC mRNA expression was also significantly inhibited. These results indicate that the 15-member macrolide, AZM, exerts direct inhibitory effects on mucus secretion from airway epithelial cells and that it may be useful for the treatment of mucus hypersecretion caused by allergic inflammation and LPS stimulation.
\end{abstract}

\section{Introduction}

The 14-member macrolides, clarithromycin (CAM) and erythromycin (EM), and the 15-member macrolide, azithromycin (AZM), are widely used for the treatment of airway inflammation. Low-dose, long-term macrolide therapy has been reported to be very effective for patients with chronic airway diseases, such as diffuse panbronchiolitis [1], chronic bronchitis [2,3], and chronic rhinosinusitis [4, 5]. It has been suggested that these effects depend on anti-inflammatory and immunomodulatory actions of 14- and 15-member macrolides rather than antibacterial one.

Hypersecretion of mucus is an important characteristic of these airway inflammations. The clinical effectiveness of macrolide therapy was represented by a significant reduction in the amount of secreted mucus. In our previous study, oral administration of CAM or EM significantly inhibited lipopolysaccharides- (LPS-) induced and antigen-induced mucus production in rat nasal epithelium, whereas 16member macrolide, josamycin (JM), showed no effect. CAM and EM also inhibited mucus secretion from cultured airway epithelial cells, NCI-H292 cells, and human nasal epithelial cells cultured in air-liquid interface $[6,7]$. These results indicate that the 14-member macrolides, CAM and EM, exert direct inhibitory effects on mucus secretion from airway epithelial cells. However, the inhibitory effect of 15 -member macrolide, AZM, on mucus secretion is less well studied compared with CAM and EM.

In the present study, to demonstrate the effects of AZM on mucus secretion from airway epithelial cells, we evaluated (1) the in vivo effects of AZM on antigen-induced and LPS-induced mucus production in rat nasal epithelium, and (2) the in vitro effects on tumor necrosis factor- $\alpha$ (TNF- $\alpha-$ ) induced mucus secretion from human mucoepidermoid carcinoma cells (NCI-H292 cells) and from human nasal epithelial cells cultured in air-liquid interface. Mucus 
secretion was evaluated by enzyme-linked immunosorbent assay (ELISA) using an anti-MUC5AC monoclonal antibody that recognizes peptide backbones of mucin. The effect on mRNA expression of MUC5AC gene was also examined.

\section{Methods}

2.1. Mucus Hypersecretion in Rat Nasal Epithelium. All experiments were approved by the Committee for the Care and Use of Laboratory Animals of Mie University School of Medicine. Sensitization and challenge of rats were performed as previously reported [8]. Male Fisher 344 rats (6 weeks old) were immunized with intraperitoneal injection of $200 \mu \mathrm{g}$ ovalbumin (OVA, grade V; Sigma Chemical Co., St. Louis, $\mathrm{MO})$ and $10 \mathrm{mg}$ of $\mathrm{Al}(\mathrm{OH})_{3}$ at days 1, 2, 3, and 11. At day $19,0.1 \mathrm{~mL}$ saline containing $10 \mathrm{mg}$ of OVA was instilled into nasal cavity for 3 days. For LPS stimulation, rats ( 9 weeks old) were intranasally instilled with $0.1 \mathrm{~mL}$ saline containing $0.1 \mathrm{mg}$ LPS from Escherichia coli 0111:B4 (Sigma) for 3 days [9].

AZM (5-10 mg/kg, Pfizer Pharmaceutical, Tokyo), CAM (5-10 mg/kg, Taisho Pharmaceutical, Tokyo), JM (10 mg/kg, Yamanouchi Pharmaceutical, Tokyo), or ampicillin (ABPC, $30 \mathrm{mg} / \mathrm{kg}$, Sigma) in $0.5 \%$ carboxymethyl cellulose sodium salt was given orally 1 hour before the intranasal instillation of OVA or LPS for 3 days. Twenty-four hours after the last intranasal instillation of OVA or LPS, rats were sacrificed, and the nasal cavity was transversely sectioned at the level of incisive papilla. Paraffin sections were stained with alcian blue-periodic acid-Schiff and hematoxylin (AB-PAS-H).

2.2. Morphometry. The percentage area of AB-PAS-stained mucosubstance in the surface epithelium was determined with the image analyzer (SP 500, Olympus, Tokyo) [9]. The area of nasal epithelium was outlined, and the image analyzer determined the area of AB-PAS-stained mucosubstance within this reference area. The percentage area of mucosubstance per epithelial area was calculated over $2 \mathrm{~mm}$ $(1 \mathrm{~mm}$ of each side of nasal septum $\times 2$ ) of the basal lamina at the center of septal cartilage. Since the measured area of mucosubstance changes in the oblique section, the percent area of mucosubstance was used as a parameter of intraepithelial mucus production.

2.3. Cell Cultures. A human mucoepidermoid carcinoma cell line, NCI-H292, was grown on plastic dish in RPMI 1640 medium containing $10 \%$ fetal bovine serum, penicillin streptomycin $(50 \mathrm{U} / \mathrm{mL}-50 \mu \mathrm{g} / \mathrm{mL})$, and Hepes $(25 \mathrm{mM})$.

Human nasal epithelial cells were obtained from nasal polyps from patients with chronic sinusitis. The dissociated epithelial cells were cultured in a serum-free hormone supplement medium according to a technique described previously [10]. An air-liquid interface was created when the cells became confluent, and the cultures were supplemented with medium containing $5 \times 10^{-8} \mathrm{M}$ retinoic acid.

When the NCI-H292 cells become confluent, or at the 14-day culture in the air-liquid interface of nasal epithelial cells, tumor necrosis factor- $\alpha$ (TNF- $\alpha$ ), and AZM, CAM, $\mathrm{JM}$, or ABPC was added to the culture medium ( $\mathrm{pH} 7.2$ ) for 24 hours, then the culture medium and total RNA were collected.

2.4. ELISA. The culture medium were incubated at $40^{\circ} \mathrm{C}$ in a 96-well plate, until dry. Plates were blocked with $2 \%$ BSA for 1 hour, and then incubated with $50 \mu \mathrm{L}$ of mouse monoclonal MUC5AC antibody (1:100) for 1 hour. The wells were incubated with $100 \mu \mathrm{L}$ of horseradish peroxidasegoat anti-mouse IgG conjugate $(1: 10,000)$ for 1 hour. Color reaction was developed using $3,3^{\prime}, 5,5^{\prime}$-tetramethylbenzidine peroxidase solution. Absorbance was read at $450 \mathrm{~nm}$.

2.5. Reverse Transcription-Polymerase Chain Reaction (RT$P C R)$. Total RNA was extracted from cultured cells, reverse transcribed, then the cDNA was amplified by PCR using the Superscript preamplification system kit (Gibco, Grand Island, NY). The MUC5AC cDNA was amplified using the sense primer $5^{\prime}$-CACCAAATACGCCAACAAGAC- $3^{\prime}$ and the antisense primer 5'-CAGGGCCACGCAGCCAGAGAA$3^{\prime}$. The GAPDH cDNA was amplified using the sense primer $5^{\prime}$-CCACCCATGGCAAATTCCATGGCA- ${ }^{\prime}$ and the antisense primer $5^{\prime}$-TCTAGACGGCAGGTCAGGTCCACC$3^{\prime}$.

2.6. Statistics. All data are expressed as mean \pm SD. The difference between variables was analyzed by the MannWhitney $U$ test. Probability values of $P<0.05$ were considered significant.

\section{Results}

3.1. In Vivo Effects on Mucus Production. Intranasal instillation of OVA for 3 consecutive days induced hypertrophic and metaplastic changes of goblet cells in nasal septal epithelium of OVA-sensitized rats. Similar changes of goblet cells occurred after 3 days of LPS instillation. Only a few goblet cells were observed in control groups (untreated control, saline-instilled, and sham-sensitized rats challenged with saline or OVA, and OVA-sensitized rats challenged with saline).

Oral administration of AZM (5-10 mg/kg) or CAM (5$10 \mathrm{mg} / \mathrm{kg}$ ) significantly inhibited OVA-induced mucus production, whereas treatment with JM (16-member macrolide) or ABPC showed no significant effect (Figure 1). OVAsensitized rats, challenged with OVA, showed significant infiltration of eosinophils in nasal septal mucosa, however, AZM had no effect on OVA-induced eosinophil infiltration. The number of eosinophils in nasal septal mucosa $/ 8 \mathrm{~mm}$ ( $4 \mathrm{~mm}$ in each side $\times 2$ ) was $2.6 \pm 1.8$ (saline control), $47.2 \pm$ 17.7 (OVA-induced control), $51.4 \pm 18.3$ (AZM $5 \mathrm{mg} / \mathrm{kg}$ ), and $44.4 \pm 26,2$ (AZM $10 \mathrm{mg} / \mathrm{kg}$ ). LPS-induced mucus production was also significantly inhibited by the treatment with AZM $(10 \mathrm{mg} / \mathrm{kg})$ or CAM $(10 \mathrm{mg} / \mathrm{kg})$, whereas JM or ABPC showed no effect (Figure 2). 


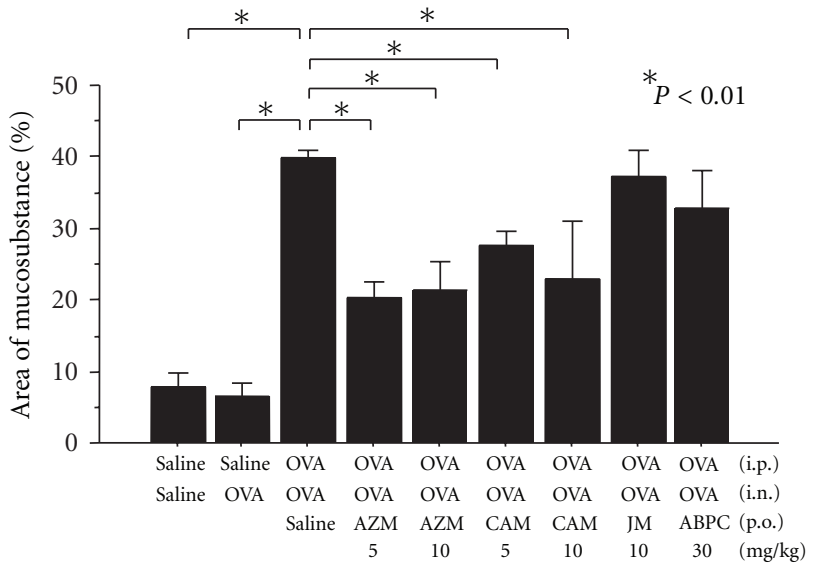

FIGURE 1: Effects of azithromycin (AZM, 5-10 mg/kg), clarithromycin (CAM, 5-10 mg/kg), josamycin (JM, $10 \mathrm{mg} / \mathrm{kg}$ ), or ampicillin (ABPC, $30 \mathrm{mg} / \mathrm{kg}$ ) on OVA-induced mucus production in OVAsensitized rats $(n=6)$. Significant increase in intraepithelial mucosubstance occurred 24 hours after 3 days of OVA instillation. Oral administration of AZM or CAM significantly inhibited antigeninduced mucus production, whereas JM and ABPC had no effect.

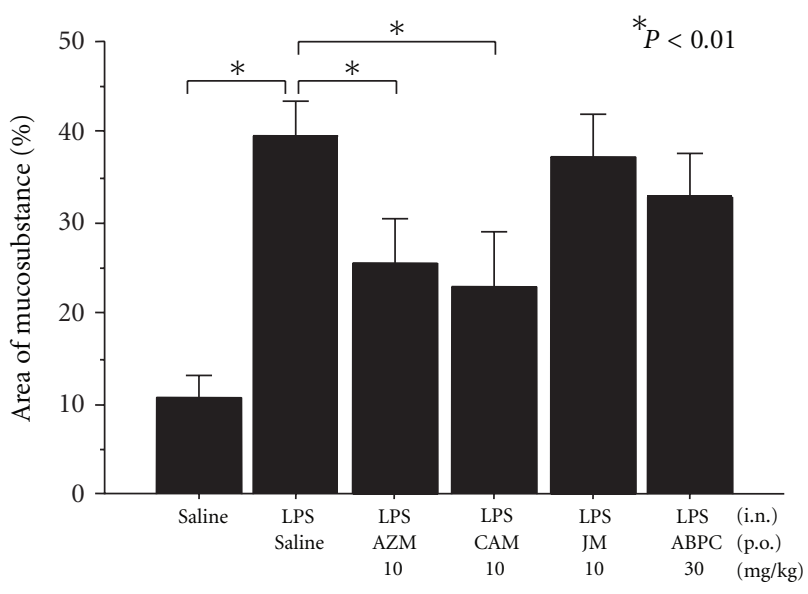

FIGURE 2: Effects of azithromycin (AZM, $10 \mathrm{mg} / \mathrm{kg}$ ), clarithromycin (CAM, $10 \mathrm{mg} / \mathrm{kg}$ ), josamycin (JM, $10 \mathrm{mg} / \mathrm{kg}$ ), or ampicillin (ABPC, $30 \mathrm{mg} / \mathrm{kg}$ ) on LPS-induced mucus production in rat nasal epithelium $(n=6)$. Significant increase in intraepithelial mucosubstance occurred 24 hours after 3 days of LPS instillation. Oral administration of AZM or CAM significantly inhibited LPS-induced mucus production, whereas JM and ABPC had no effect.

\subsection{In Vitro Effects on Mucin Secretion}

3.2.1. NCI-H292 Cells. TNF- $\alpha$ significantly stimulated mucin secretion from NCI-H292 cells. The percentage stimulation of MUC5AC secretion was $44.0 \% \pm 8.6 \%$. AZM showed an inhibitory effect on TNF- $\alpha$-induced MUC5AC secretion at $10^{-6}-10^{-8} \mathrm{M}$. CAM $\left(10^{-6}-10^{-7} \mathrm{M}\right)$ also significantly inhibited TNF- $\alpha$-induced mucin secretion, whereas JM (16-member macrolide) and ABPC showed no effects (Figure 3).
3.2.2. Human Nasal Epithelial Cells. At the 14-day culture in air-liquid interface condition, secretory cell differentiation was induced in about $25 \%$ of cultured cells [10]. The medium in the lower compartment did not react with MUC5AC. Only the samples collected from the apical side contained MUC5AC-reactive mucin, indicating that there was a polarity in mucin secretion. TNF- $\alpha(20 \mathrm{ng} / \mathrm{mL})$ significantly stimulated MUC5AC secretion, and AZM significantly inhibited TNF- $\alpha$-induced mucin secretion at $10^{-4} \mathrm{M}$ from cultured human nasal epithelial cells, whereas ABPC showed no effect. Changes of MUC5AC gene expression were evaluated by RT-PCR, and AZM $\left(10^{-4} \mathrm{M}\right)$ significantly inhibited MUC5AC mRNA expression of cultured human nasal epithelial cells (Figure 4).

\section{Discussion}

In the present study, hypertrophic and metaplastic changes of goblet cells were induced in rat nasal epithelium by intranasal challenge with OVA in OVA-sensitized rats or by intranasal LPS instillation. A similar increase of epithelial mucosubstance occurred 24 hours after three days of OVA or LPS instillation. Oral administration of AZM (15-member macrolide) significantly inhibited antigen- or LPS-induced mucus production. These inhibitory effects are similar with CAM (14-member macrolide), whereas JM (16-member macrolide) or ABPC showed no effect. This is the first report showing the in vivo effects of AZM on mucus production in upper airways.

Mucus hypersecretion associated with hypertrophy and metaplasia of epithelial secretory cells is a major characteristic of chronic airway diseases, and the clinical effectiveness of low-dose and long-term treatment with 14-member macrolides, CAM and EM, is represented by the significant reduction of the amount of secreted mucus, sputum, and rhinorrhea. Tamaoki and coworkers [11] have reported that erythromycin (EM) significantly inhibited mucus secretion in guinea pig trachea in vivo. In our previous studies $[6,7]$, CAM and EM inhibited antigen- and LPS-induced mucus production in rat nasal epithelium. CAM and EM showed the direct inhibitory effect on mucin secretion from cultured airway epithelial cells [6].

The 15-member macrolide, AZM, also has an antiinflammatory action, and AZM has been widely used for the treatment of patients with chronic airway inflammation, such as cystic fibrosis [12], chronic obstructive pulmonary disease [13], and bronchiolitis obliterans syndrome [14]. The meta-analysis study revealed that long-term use of AZM in cystic fibrosis patients improved the lung function, especially for Pseudomonas aeruginosa-colonized patients [12]. A large randomized placebo-controlled study revealed that longterm use of AZM decreased the risk of acute exacerbations of patients with chronic obstructive pulmonary diseases [13].

Several animal studies demonstrated that AZM attenuated many types of experimental airway inflammation caused by the allergic inflammation [15], by the inhalation of irritant gas, ozone [16], by the lung ischemia reperfusion injury [17], or by bacterial and viral infections [18, 19] 


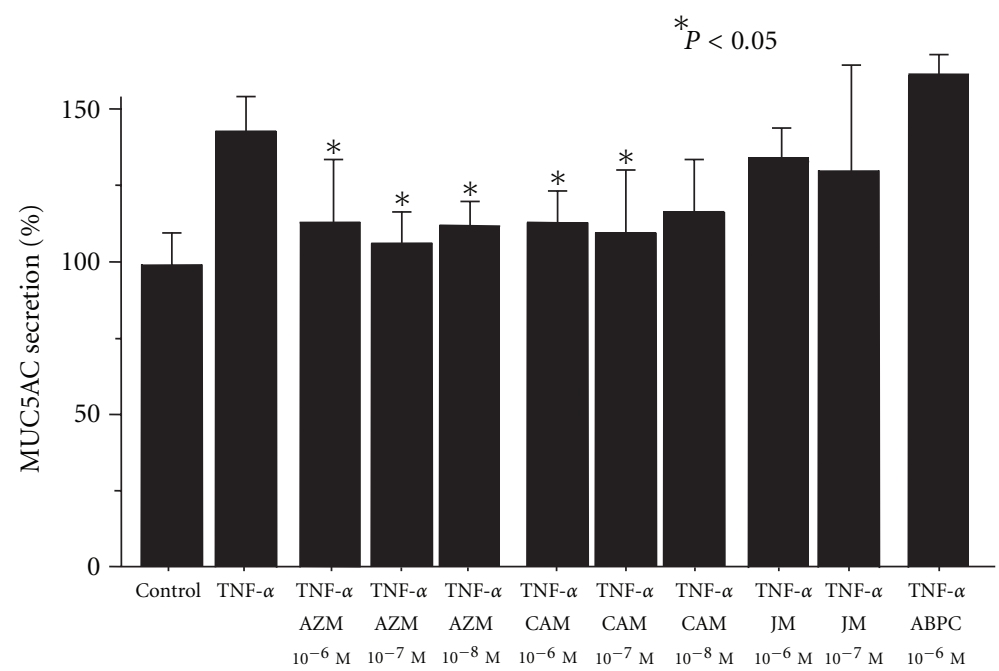

Figure 3: Effects of azithromycin (AZM), clarithromycin (CAM), josamycin (JM), and ampicillin (ABPC) on TNF- $\alpha$ (20 ng/mL)-induced MUC5AC secretion from NCI-H292 cells $(n=5)$. TNF- $\alpha$ stimulated mucin secretion. AZM and CAM significantly inhibited TNF- $\alpha$-induced MUC5AC secretion, whereas JM and ABPC had no effect.

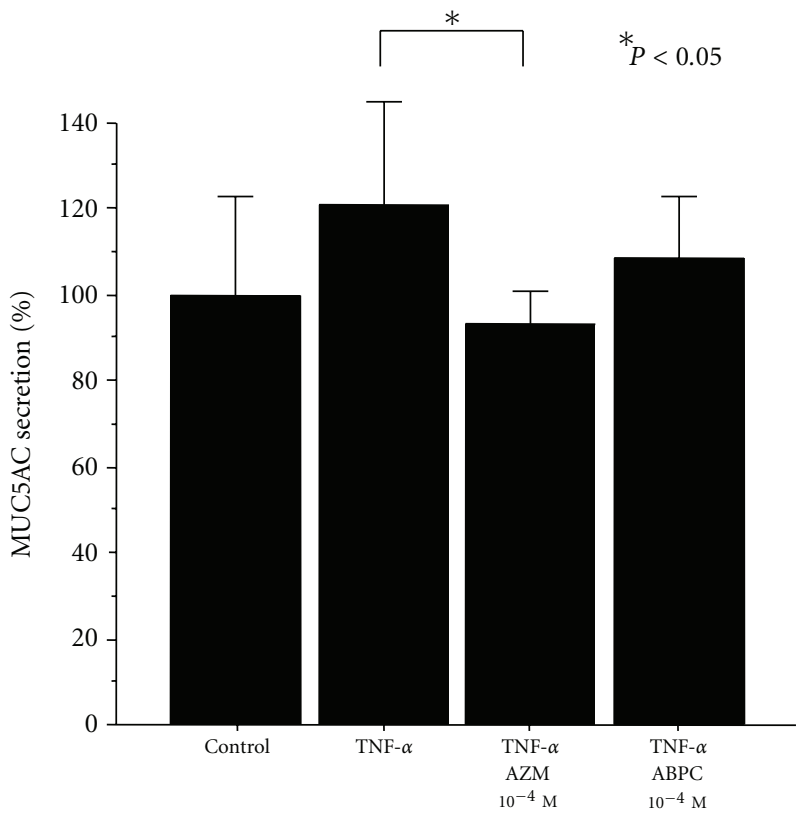

(a)

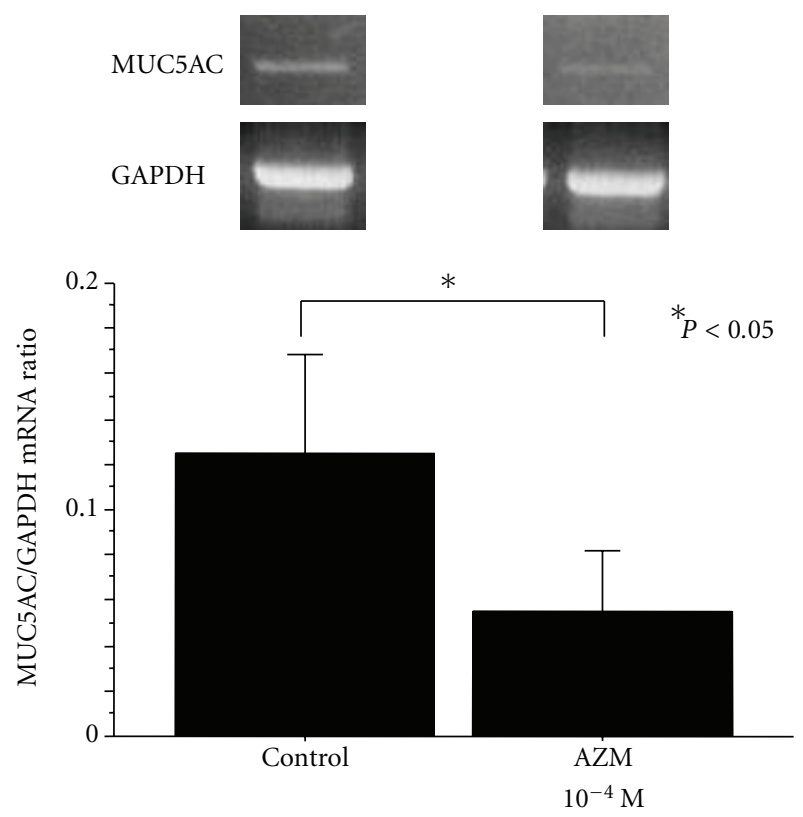

(b)

FIGURE 4: Effects of azithromycin (AZM) and ampicillin (ABPC) on TNF- $\alpha$ (20 ng/mL)-induced mucin secretion (a) and MUC5AC mRNA expression (b) from human nasal epithelial cells cultured at air-liquid interface $(n=5)$. (a) TNF- $\alpha$ stimulated MUC5AC secretion, and AZM significantly inhibited TNF- $\alpha$-induced mucin secretion at $10^{-4} \mathrm{M}$, whereas ABPC showed no effect. (b) Total RNA was isolated and analyzed for MUC5AC and GAPDH mRNA expression by RT-PCR $(n=5)$. AZM significantly inhibited MUC5AC mRNA expression at $10^{-4} \mathrm{M}^{2}$ demonstrated by the MUC5AC/GAPDH ratio.

in lower airways. In the present study, AZM also attenuated antigen- or LPS-induced mucus production in rat nasal epithelium. Many investigators demonstrated the antiinflammatory action of AZM, which includes the immunomodulatory effects on inflammatory cells $[19,20]$, the modulation of cytokine production [21], and the inhibition of bacterial function and biofilm formation [22].
Recently, several in vitro studies have demonstrated the inhibitory effects of AZM on mucus secretion from airway epithelium. AZM inhibited MUC5AC expression and secretion from NCI-H292 cells, induced by human neutrophil peptide-1 and LPS [23], by Pseudomonas aeruginosaderived N-(3-Oxododecanoyl) homoserine lactone [24], or by nontypable Haemophilus influenza and Chlamydophilia 
pneumoniae $[25,26]$. AZM inhibited acetylcholine-induced MUC5AC release from swine airway submucosal gland cells [27]. In the present study, we examined the TNF- $\alpha$-induced MUC5AC secretion from airway epithelial cells. TNF- $\alpha$ has been implicated in LPS-induced airway inflammation. LPS stimulation enhanced the TNF- $\alpha / \beta$ generation in rat lung [28], and TNF- $\alpha$ antagonist inhibited the LPS-induced mucus hypersecretion in rat nasal epithelium [29]. We found that AZM and CAM significantly inhibited TNF- $\alpha$ induced MUC5AC secretion from NCI-H292 cells. AZM also inhibited mucin secretion from human nasal epithelial cells cultured in air-liquid interface, and MUC5AC mRNA expression was significantly inhibited. This is the first report showing the inhibitory effects of AZM on mucus secretion from normal human airway epithelial cells. These inhibitory actions appeared to be unique for 14- and 15-member macrolides because other antibiotics, JM (16member macrolide) and ABPC, did not show any effect.

In our previous study, the active concentrations of CAM and EM for the inhibition of mucin secretion are $10^{-6}$ to $10^{-7} \mathrm{M}$ for NCI-H292 cells and $10^{-4}$ to $10^{-5} \mathrm{M}$ for human nasal epithelial cells [6]. The different results may be caused by the different responses between mucoepidermoid carcinoma cells and normal nasal epithelial cells. In the present study, AZM showed the similar inhibitory effect on MUC5AC secretion from NCI-H292 cells and from human nasal epithelial cells. It is well known that the macrolide antibiotics achieve higher concentration in airway tissues, and the therapeutic concentrations are $10^{-5}$ to $10^{-6} \mathrm{M}$ in tissues. In our in vivo study, oral administration of 5$10 \mathrm{mg} / \mathrm{kg}$ AZM or CAM significantly inhibited epithelial mucus production, and a previous study demonstrated that this is comparable with tissue concentration of $10^{-5}$ to $10^{-6} \mathrm{M}$ in rats [30]. These results indicate that the in vivo effect of AZM or CAM is caused in some parts by the direct inhibitory effect on mucus secretion from the epithelial cells.

\section{Conclusion}

We have induced hypertrophic and metaplastic changes of goblet cells in rat nasal epithelium by intranasal challenge with OVA in OVA-sensitized rat and by LPS instillation, and we have demonstrated in this model that AZM inhibits epithelial mucus production produced by allergic inflammation and by LPS stimulation. We have also demonstrated that AZM directly inhibits MUC5AC secretion from NCI-H292 cells and human nasal epithelial cells. These novel findings may explain the clinical efficacy of AZM in patients with chronic airway inflammation.

\section{References}

[1] S. Kudoh, A. Azuma, M. Yamamoto, T. Izumi, and M. Ando, "Improvement of survival in patients with diffuse panbronchiolitis treated with low-dose erythromycin," American Journal of Respiratory and Critical Care Medicine, vol. 157, no. 6, pp. 1829-1832, 1998.

[2] T. Shirai, A. Sato, and K. Chida, "Effect of 14-membered ring macrolide therapy on chronic respiratory tract infections and polymorphonuclear leukocyte activity," Internal Medicine, vol. 34, no. 6, pp. 469-474, 1995.

[3] K. Oishi, F. Sonoda, S. Kobayashi et al., "Role of interleukin8 (IL-8) and an inhibitory effect of erythromycin on IL-8 release in the airways of patients with chronic airway diseases," Infection and Immunity, vol. 62, no. 10, pp. 4145-4152, 1994.

[4] K. Fujita, T. Shimizu, Y. Majima, and Y. Sakakura, "Effects of macrolides on interleukin-8 secretion from human nasal epithelial cells," European Archives of Oto-Rhino-Laryngology, vol. 257, no. 4, pp. 199-204, 2000.

[5] T. Yamada, S. Fujieda, S. Mori, H. Yamamoto, and H. Saito, "Macrolide treatment decreased the size of nasal polyps and IL-8 levels in nasal lavage," American Journal of Rhinology, vol. 14, no. 3, pp. 143-148, 2000.

[6] T. Shimizu, S. Shimizu, R. Hattori, E. C. Gabazza, and Y. Majima, "In vivo and in vitro effects of macrolide antibiotics on mucus secretion in airway epithelial cells," American Journal of Respiratory and Critical Care Medicine, vol. 168, no. 5, pp. 581-587, 2003.

[7] Y. Takahashi, T. Shimizu, and Y. Sakakura, "Effects of indomethacin, dexamethasone, and erythromycin on endotoxininduced intraepithelial mucus production of rat nasal epithelium," Annals of Otology, Rhinology and Laryngology, vol. 106, no. 8, pp. 683-687, 1997.

[8] T. Shimizu, H. Hirano, Y. Majima, and Y. Sakakura, "A mechanism of antigen-induced mucus production in nasal epithelium sensitized rats: a comparison with lipopolysaccharideinduced mucus production," American Journal of Respiratory and Critical Care Medicine, vol. 161, no. 5, pp. 1648-1654, 2000.

[9] T. Shimizu, Y. Takahashi, S. Kawaguchi, and Y. Sakakura, "Hypertrophic and metaplastic changes of goblet cells in rat nasal epithelium induced by endotoxin," American Journal of Respiratory and Critical Care Medicine, vol. 153, no. 4, pp. 1412-1418, 1996.

[10] S. Usui, T. Shimizu, K. Fujita, C. Kishioka, and Y. Sakakura, "Secretory cell differentiation and mucus secretion in cultures of human nasal epithelial cells: use of a monoclonal antibody to study human nasal mucin," Annals of Otology, Rhinology and Laryngology, vol. 109, no. 3, pp. 271-277, 2000.

[11] J. Tamaoki, K. Takeyama, I. Yamawaki, M. Kondo, and K. Konno, "Lipopolysaccharide-induced goblet cell hypersecretion in the guinea pig trachea: inhibition by macrolides," American Journal of Physiology, vol. 272, no. 1, pp. L15-L19, 1997.

[12] Y. Cai, D. Chai, R. Wang, N. Bai, B. B. Liang, and Y. Liu, "Effectiveness and safety of macrolides in cystic fibrosis patients: a meta-analysis and systemic review," Journal of Antimicrobial Chemotherapy, vol. 66, pp. 968-978, 2011.

[13] R. K. Albert, J. Connett, W. C. Bailey et al., "Azithromycin for prevention of exacerbations of COPD," The New England Journal of Medicine, vol. 365, pp. 689-698, 2011.

[14] S. G. Gerhardt, J. F. McDyer, R. E. Girgis, J. V. Conte, S. C. Yang, and J. B. Orens, "Maintenance azithromycin therapy for bronchiolitis obliterans syndrome: results of a pilot study," American Journal of Respiratory and Critical Care Medicine, vol. 168, no. 1, pp. 121-125, 2003.

[15] A. Beigelman, S. Gunsten, C. L. Mikols et al., "Azithromycin attenuates airway inflammation in a noninfectious mouse model of allergic asthma," Chest, vol. 136, no. 2, pp. 498-506, 2009.

[16] G. I. Criqui, C. Solomon, B. S. Welch, R. E. Ferrando, H. A. Boushey, and J. R. Balmes, "Effects of azithromycin on ozone- 
induced airway neutrophilia and cytokine release," European Respiratory Journal, vol. 15, no. 5, pp. 856-862, 2000.

[17] N. Geudens, L. Timmermans, H. Vanhooren et al., "Azithromycin reduces airway inflammation in a murine model of lung ischaemia reperfusion injury," Transplant International, vol. 21, no. 7, pp. 688-695, 2008.

[18] A. Beigelman, C. L. Mikols, S. P. Gunsten, C. L. Cannon, S. L. Brody, and M. J. Walter, "Azithromycin attenuates airway inflammation in a mouse model of viral bronchiolitis," Respiratory Research, vol. 11, article 90, 2010.

[19] W. C. Tsai, M. L. Rodriguez, K. S. Young et al., "Azithromycin blocks neutrophil recruitment in Pseudomonas endobronchial infection," American Journal of Respiratory and Critical Care Medicine, vol. 170, no. 12, pp. 1331-1339, 2004.

[20] D. J. Feola, B. A. Garvy, T. J. Cory et al., "Azithromycin alters macrophage phenotype and pulmonary compartmentalization during lung infection with Pseudomonas," Antimicrobial Agents and Chemotherapy, vol. 54, no. 6, pp. 2437-2447, 2010.

[21] H. Yamasawa, K. Oshikawa, S. Ohno, and Y. Sugiyama, "Macrolides inhibit epithelial cell-mediated neutrophil survival by modulating granulocyte macrophage colony-stimulating factor release," American Journal of Respiratory Cell and Molecular Biology, vol. 30, no. 4, pp. 569-575, 2004.

[22] I. Perez-Martinez and D. Haas, "Azithromycin inhibits expression of the GacA-dependent small RNAs RsmY and Rsm $\mathrm{Z}$ in Pseudomonas aeruginosa," Antimicrobial Agents and Chemotherapy, vol. 55, pp. 3399-3405, 2011.

[23] H. Ishimoto, H. Mukae, N. Sakamoto et al., "Different effects of telithromycin on MUC5AC production induced by human neutrophil peptide-1 or lipopolysaccharide in NCI-H292 cells compared with azithromycin and clarithromycin," Journal of Antimicrobial Chemotherapy, vol. 63, no. 1, pp. 109-114, 2009.

[24] Y. Imamura, K. Yanagihara, Y. Mizuta et al., "Azithromycin inhibits MUC5AC production induced by the Pseudomonas aeruginosa autoinducer $\mathrm{N}$-(3-oxododecanoyl) homoserine lactone in NCI-H292 cells," Antimicrobial Agents and Chemotherapy, vol. 48, no. 9, pp. 3457-3461, 2004.

[25] N. Araki, K. Yanagihara, Y. Morinaga et al., "Azithromycin inhibits nontypeable Haemophilus influenzae-induced MUC5AC expression and secretion via inhibition of activator protein-1 in human airway epithelial cells," European Journal of Pharmacology, vol. 644, no. 1-3, pp. 209-214, 2010.

[26] Y. Morinaga, K. Yanagihara, N. Miyashita et al., "Azithromycin, clarithromycin and telithromycin inhibit MUC5AC induction by Chlamydophila pneumoniae in airway epithelial cells," Pulmonary Pharmacology and Therapeutics, vol. 22, no. 6, pp. 580-586, 2009.

[27] S. Lu, H. Liu, and J. M. Farley, "Macrolide antibiotics inhibit mucus secretion and calcium entry in swine airway submucosal mucous gland cells," Journal of Pharmacology and Experimental Therapeutics, vol. 336, no. 1, pp. 178-187, 2011.

[28] M. Ermert, C. Pantazis, H. R. Duncker, F. Grimminger, W. Seeger, and L. Ermert, "In situ localization of TNF $\alpha / \beta$, TACE AND TNF receptors TNF-R1 and TNF-R2 in control and LPStreated lung tissue," Cytokine, vol. 22, no. 3-4, pp. 89-100, 2003.

[29] D. H. Kim, E. J. Jeon, S. N. Park, K. H. Park, Y. S. Park, and S. W. Yeo, "Effects of a tumor necrosis factor- $\alpha$ antagonist on experimentally induced rhinosinusitis," Journal of Biomedicine and Biotechnology, vol. 2011, Article ID 360457, 9 pages, 2011.

[30] H. Yoshida and T. Furuta, "Tissue penetration properties of macrolide antibiotics-comparative tissue distribution of erythromycin-stearate, clarithromycin, roxythromycin and azithromycin in rats," Japanese Journal of Antibiotics, vol. 52, pp. 497-503, 1999. 


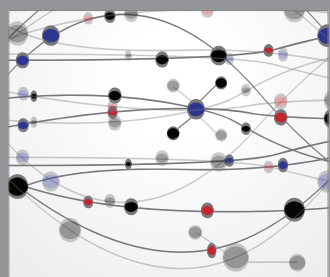

The Scientific World Journal
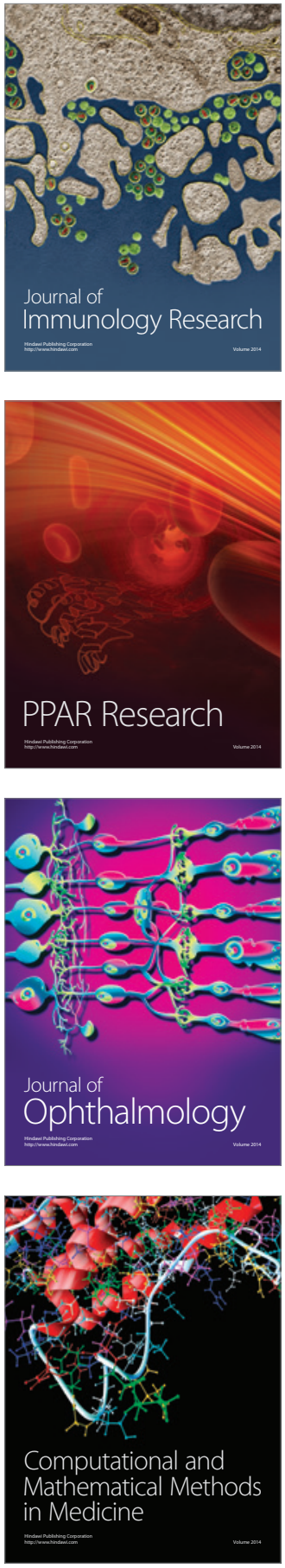

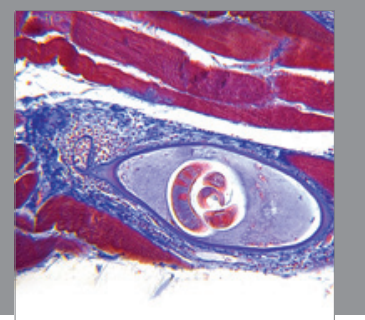

Gastroenterology

Research and Practice
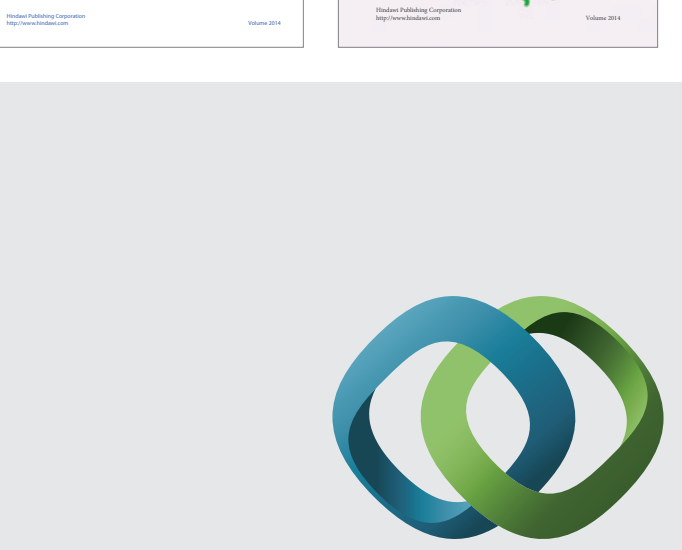

\section{Hindawi}

Submit your manuscripts at

http://www.hindawi.com
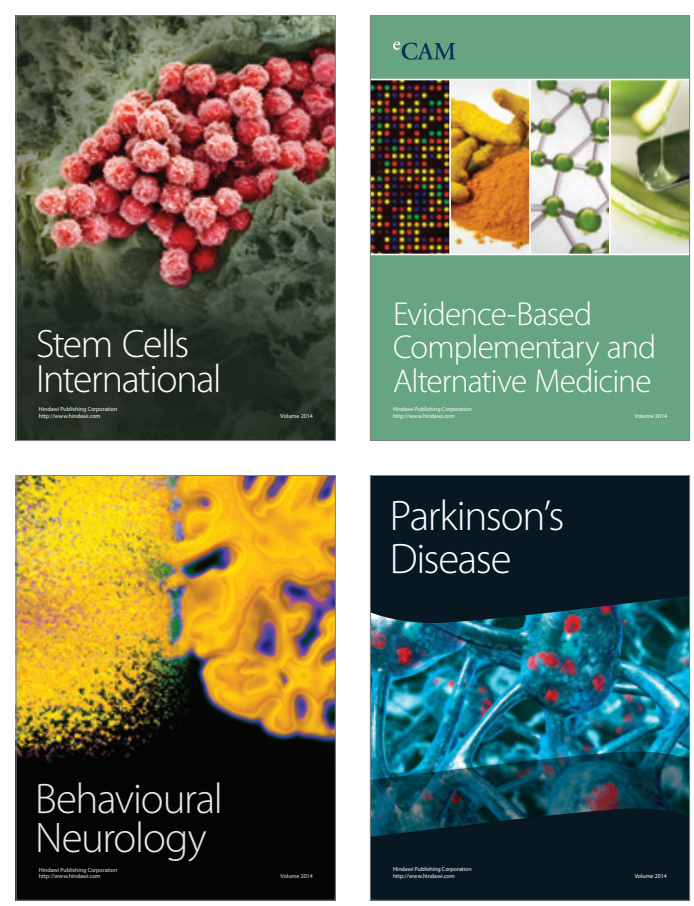

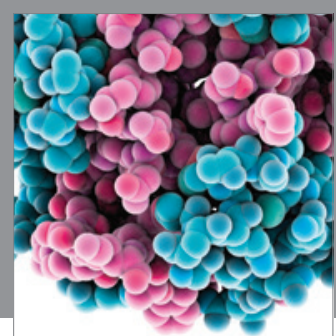

Journal of
Diabetes Research

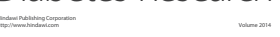

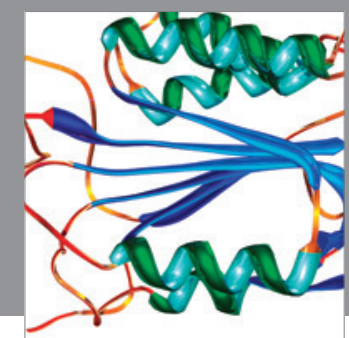

Disease Markers
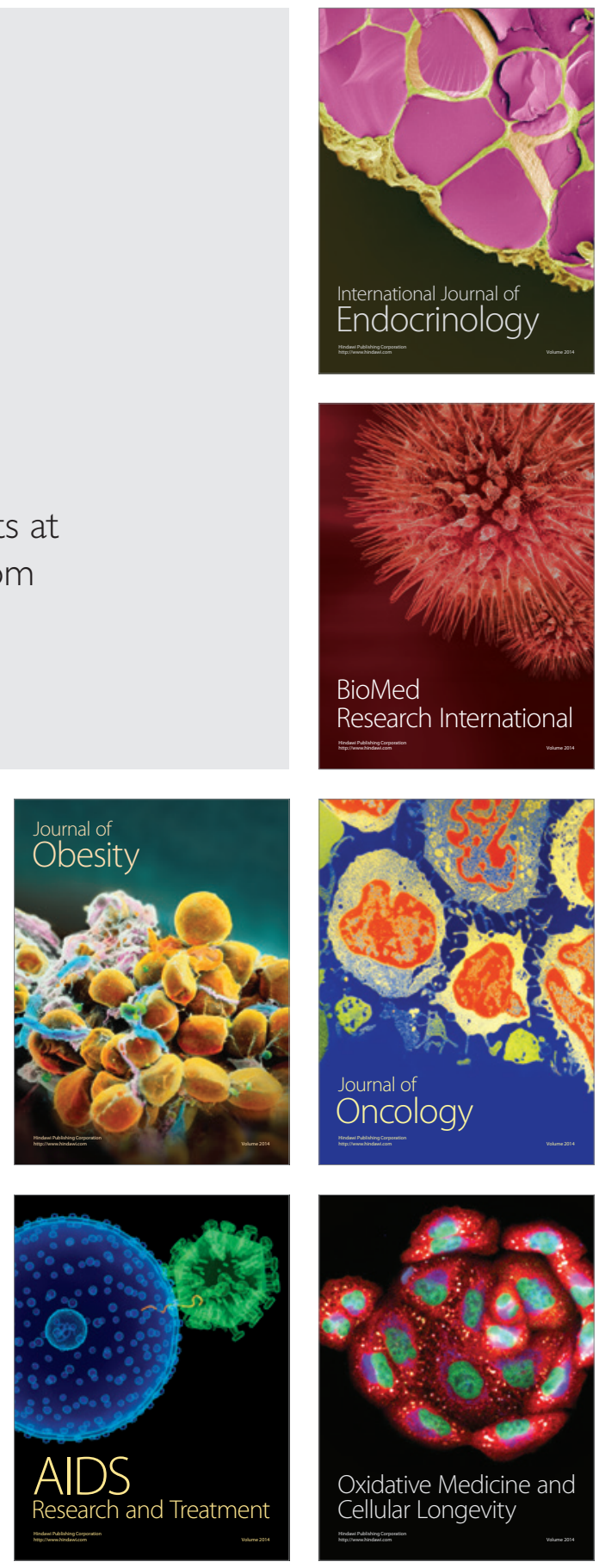